\title{
Sex differences in fetal Doppler parameters during gestation
}

\author{
Dakshita Jagota', Hannah George ${ }^{1}$, Melissa Walker ${ }^{2,3}$, Anjana Ravi Chandran², Natasha Milligan ${ }^{4}$, Shiri Shinar $^{2}$, \\ Clare L. Whitehead ${ }^{5}$, Sebastian R. Hobson ${ }^{2}$, Lena Serghides ${ }^{6,7,8}$, W. Tony Parks ${ }^{9,10}$, Ahmet A. Baschat ${ }^{11}$, \\ Christopher K. Macgowan ${ }^{12,13}$, John G. Sled ${ }^{3,12,13,14}$, John C. Kingdom²,3 and Lindsay S. Cahill ${ }^{{ }^{*}}$ (D)
}

\begin{abstract}
Background: Fetal sex is known to affect pregnancy outcomes. In current clinical practice, monitoring of fetal wellbeing is based on Doppler ultrasound measurements of major placental and fetal vessels. The objective of this study was to investigate the effect of fetal sex on Doppler parameters throughout gestation in healthy pregnancy.

Methods: A prospective study was conducted in 240 pregnant women with ultrasound examinations at a 4-weekly interval between 12 and 38 weeks of gestation. Pulsed Doppler spectra were collected for the umbilical arteries (UAs), middle cerebral artery (MCA), descending abdominal aorta (DAo), and ductus venosus (DV). Linear mixed effects models were used to determine if the pulsatility indices (PIs) of these vessels depended on gestational age and fetal sex.

Results: While there were no differences in the MCA PI and DV PIV over gestation between female and male fetuses, the trajectory of the UA and DAo Pls differed by fetal $\operatorname{sex}(p=0.02$ and $p=0.01$, respectively).

Conclusions: Doppler ultrasound parameters were found to be dependent on fetal sex for some vessels and not for others in healthy pregnancies. Further investigations are needed to understand the physiological mechanisms for these sex differences and the relevance for disease processes in pregnancy.
\end{abstract}

Keywords: Doppler ultrasound, Fetal sex, Pregnancy, Pulsatility index, Sex differences

\section{Introduction}

There is a growing body of known sex differences in fetal and placental development, highlighting the importance of incorporating fetal sex as a biological variable in experimental designs and in clinical decision-making. A recent systematic review and meta-analysis concluded that fetal sex is associated with multiple maternal pregnancy complications including term preeclampsia and gestational diabetes [1]. This phenomenon is consistent with sex-specific differences in hemodynamic markers of placental and

\footnotetext{
* Correspondence: Icahill@mun.ca

1 Department of Chemistry, Memorial University of Newfoundland, 283 Prince Philip Drive, St. John's, NL A1B 3X7, Canada

Full list of author information is available at the end of the article
}

fetal maturation measured using Doppler ultrasound. Sex differences during the second half of gestation in healthy pregnancies have been reported for the umbilical artery (UA) pulsatility index (PI) [2] and the cerebroplacental and umbilicocerebral ratios [3]. Immediately prior to the onset of active labor, the middle cerebral artery (MCA) PI and umbilical venous flow were found to depend on fetal sex [4].

Ultrasound is the standard-of-care method for assessment of fetal well-being during pregnancy. Reference ranges for ultrasound-derived measures of placental and fetal health are well established [5-11]; however, these do not take into account fetal sex differences. In the present study, we investigated the effect of fetal sex on the pulsatility indices of the UA, MCA, descending

(c) The Author(s). 2021 Open Access This article is licensed under a Creative Commons Attribution 4.0 International License, which permits use, sharing, adaptation, distribution and reproduction in any medium or format, as long as you give appropriate credit to the original author(s) and the source, provide a link to the Creative Commons licence, and indicate if changes were made. The images or other third party material in this article are included in the article's Creative Commons licence, unless indicated otherwise in a credit line to the material. If material is not included in the article's Creative Commons licence and your intended use is not permitted by statutory regulation or exceeds the permitted use, you will need to obtain permission directly from the copyright holder. To view a copy of this licence, visit http://creativecommons.org/licenses/by/4.0/ The Creative Commons Public Domain Dedication waiver (http://creativecommons.org/publicdomain/zero/1.0/) applies to the data made available in this article, unless otherwise stated in a credit line to the data. 
abdominal aorta (DAo), and ductus venosus (DV) throughout gestation in a cohort of healthy pregnancies. Based on previous work [2-4], we hypothesized that the UA and MCA PI will depend on fetal sex. To our knowledge, no studies have looked at the effect of fetal sex on Doppler parameters throughout gestation for the DAo and DV.

\section{Materials and methods}

A prospective longitudinal ultrasound study was conducted at Mount Sinai Hospital (Toronto, ON, Canada) and Johns Hopkins University (Baltimore, MD, USA). The Doppler spectra were acquired as part of a study that evaluated a new methodology for measuring umbilical artery hemodynamics. The latter study, which will be reported elsewhere, dictated the study sample size and inclusion criteria. We included women between the ages of 18-45years with a healthy singleton pregnancy, a body mass index (BMI) $<45 \mathrm{~kg} / \mathrm{m}^{2}$ and no significant maternal comorbidities such as type 1 diabetes or chronic hypertension. Datasets were excluded when the patient withdrew at any point during the study, the patient had preeclampsia (diagnosed according to the ACOG definition [12]) or the neonate was small for gestational age (birth weight less than the 10th centile based on neonatal sex and gestational age [13]). Patients were recruited between 10 and 17 weeks of gestation. All patients provided written informed consent to participate in the study. The study was approved by the Institutional Review Boards of The Hospital for Sick Children (Toronto, ON, Canada; REB Number 1000051548), Mount Sinai Hospital (REB Number 150279-A), and Johns Hopkins University (IRB Number 0082717).

Ultrasound examinations were performed on a 4weekly interval between 12 and 38 weeks of gestation by certified research sonographers using either a Philips iU22 (Philips Healthcare, Andover, MA, USA) or GE Voluson e10 (GE Healthcare, Chicago, IL, USA) ultrasound system. Pulsed Doppler spectra were collected for the two UAs at the placental end, the distal portion of the MCA, the DAo at a position between the diaphragm and origin of the renal arteries, and the DV at the inlet portion [14]. The fetal heart rate and the PI for the UAs, MCA, and DAo were computed from the traced average Doppler waveforms as the difference between the peak systolic and enddiastolic velocities, divided by the mean velocity over the cardiac cycle. For the DV, the time average maximum velocity and forward velocities during the ventricular systole ( $\mathrm{S}$-wave), ventricular diastole ( $\mathrm{D}$-wave), and the atrial systole (a-wave) were measured and used to calculate the peak velocity index for veins
(PVIV) and the pulsatility index for veins (PIV) [15]. The cerebroplacental ratio was calculated as the MCA PI/UA PI [8].

All statistical tests were performed using the $\mathrm{R}$ statistical software package (www.r-project.org). The two UA PI values were averaged to provide the overall mean PI. To analyze the clinical characteristics, a one-way ANOVA was used for continuous variables to evaluate the effect of fetal sex and a Pearson's Chi-squared test was used for categorical variables. The UA PI, DAo PI, DV PVIV, and PIV data were analyzed using a linear mixed effects model with gestational age (in completed weeks), fetal heart rate, race (Asian, Black or African American, White, other), and fetal sex (female, male) as the fixed effects and a heteroscedastic random effect where inter-subject variation varied linearly with gestational age. Linear models were chosen based on previous studies of UA PI [5, 11], DAo PI [6, 9], and DV PIV [7, 10] throughout gestation. A linear mixed effects model using a second-order polynomial function was used to determine if the MCA PI and CPR depended on gestational age (in completed weeks), fetal heart rate, race, and fetal sex. A quadratic model was chosen based on previous studies $[8,11]$ and using a likelihood ratio test was shown to provide a better fit than a simpler linear model $(p<0.0001)$. A value of $p<0.05$ was taken to be significant.

\section{Results}

Two hundred and forty women consented to participate in this study. Twenty-four withdrew, 3 delivered at another site and were lost to follow-up, and 36 were excluded for adverse pregnancy outcomes (13 had preeclampsia and 23 had neonates that were small for gestational age). The 177 participants (87 females and 90 males) provided a total of $981 \mathrm{UA}, 837 \mathrm{MCA}, 937 \mathrm{DAo}$, and $774 \mathrm{DV}$ measurements. The clinical characteristics of the participants are summarized in Table 1. The maternal demographics and pregnancy and neonatal outcomes were similar between female and male fetuses, except for the fetal weight which was significantly higher in the male fetuses $(p<0.001)$.

The fetal heart rate was associated with the gestational age $(p<0.0001)$ and the Doppler indices $(p<0.0001)$. While the fetal heart rate tended to be higher in female fetuses, the difference was not statistically significant $(p=0.06)$. There was no effect of race on the PIs or the trajectory of the PIs with gestation. The pulsatility indices of the UA, MCA, DAo, and DV over gestation for female and male fetuses are shown in Fig. 1. The UA PI decreased with gestational age $(p<0.0001)$ and the rate of change with gestation depended on fetal sex $(p=0.02)$ (Fig. 1a). Starting at the beginning of the third trimester, 
Table 1 Characteristics of the study subjects meeting the inclusion criteria. Data are mean [range] or $\%(n / N)$. ${ }^{a} p<0.001$ when compared to females

\begin{tabular}{lll}
\hline Characteristic & Female $(\boldsymbol{n}=\mathbf{8 7})$ & Male $(\boldsymbol{n}=\mathbf{9 0})$ \\
\hline Maternal age at delivery (years) & $34[23-43]$ & $34[18-43]$ \\
Maternal pre-pregnancy body mass index $\left(\mathrm{kg} / \mathrm{m}^{2}\right)$ & $25.2[17.5-43.6]$ & $25.3[17.4-43.6]$ \\
Race $(\%)$ & & $18(16 / 90)$ \\
$\quad$ Asian & $25(22 / 87)$ & $13(12 / 90)$ \\
$\quad$ Black or African American & $9(8 / 87)$ & $65(58 / 90)$ \\
$\quad$ White & $62(54 / 87)$ & $4(4 / 90)$ \\
Other & $4(3 / 87)$ & $16[12-17]$ \\
Gestational age at first ultrasound visit (weeks) & $16[15-17]$ & $31(37 / 90)$ \\
Cesarean delivery (\%) & $36(31 / 87)$ & $38[30-41]$ \\
Gestational age at delivery (weeks) & $3159[1390-4390]$ & $38[31-40]$ \\
Birth weight (g) & $3422[1410-4630]^{\mathrm{a}}$ \\
\hline
\end{tabular}

the trajectory of the UA PI for the female fetuses diverged, with significantly higher values ( $4 \%$ higher at term compared to males). The relationship of the MCA PI with gestational age $(p<0.0001)$ was an inverted U-shape with a turning point at 28 weeks (Fig. 1b). Similarly, the CPR varied with gestational age as an inverted U-shape $(p<0.0001)$. There was no difference in the MCA PI or CPR over gestation between females and males. The DAo PI increased with gestational age $(p<0.0001)$ and the rate of change with gestation was significantly different between females and males $(p=0.01)$ (Fig. 1c). The DV PIV decreased with gestational age $(p<0.0001)$, and there was no difference over gestation between females and males (Fig. 1d). There was also no dependence of the DV PVIV on fetal sex (not shown).

\section{Discussion}

In the present study, we found that the pulsatility indices of the UA and DAo over gestation were dependent on fetal sex. The UA PI is routinely used as a surrogate marker of placental vascular resistance, with the goal of identifying growth-restricted fetuses that require additional surveillance $[16,17]$. Sex-specific differences in the UA PI is consistent with a recent longitudinal study by Widnes et al. [2] in healthy pregnant women. While this study also found the UA PI was elevated in female fetuses compared to males, the difference was present earlier in gestation (20-33 weeks) and equalized towards term. Conversely, we found divergence of the UA PI starting at 28 weeks of gestation. This difference may be explained by the location of the measurement along the UA (placental end vs. free loop in [2]). UA PI is known to vary along the umbilical cord, with increasing resistance observed towards the placental end $[18,19]$. For reliability, the ISUOG guidelines recommend using a fixed site (i.e., placental end) when collecting longitudinal measurements [20]. Another difference between the two studies is the study population. The average maternal age of our participants was significantly higher (34 vs. 30 years in [2]) and our birth weights were significantly lower (3290 vs. $3600 \mathrm{~g}$ in [2]), despite having a similar number of preterm births in each study (13 vs. 7 in [2]). As expected [21], the males in our study were significantly heavier at birth compared to females. While there was no difference in birth weights in Widnes et al., it has been shown that the UA PI does not depend on fetal weight [22] and therefore this difference most likely does not explain the discrepancy in the results. The difference in UA PI between females and males was small but significant ( $4 \%$ at term). The magnitude of this difference is comparable to previous work which reported the UA PI was $2.1-4.2 \%$ higher in females [2]. Although this difference does not suggest pathology in the female placentas, it may reflect a difference in placental vascular impedance that may explain sex-specific differences in pregnancy outcome. For example, early-onset preeclampsia ( $<34$ weeks' gestation) has a higher incidence in women carrying female fetuses [23-25] and has been associated with increased resistance in the umbilical arteries [26].

Similar to the UA PI, an elevated DAo PI is associated with increased fetal risk for growth restriction [27-29]. The DAo PI showed a small but significant increase throughout gestation, consistent with previous studies $[6,9]$. Moreover, the trajectory of the DAo PI over gestation differed by fetal sex with female fetuses showing a more rapid change. To our knowledge, none of the studies of DAo PI over gestation took fetal sex into account when presenting the data. In addition to providing a measurement of impedance in the placental vascular circulation, the DAo PI also represents impedance in the lower part of the fetal body. Increases in DAo PI may reflect blood flow redistribution, with blood flow being diverted away from the lower body [30]. The observation 


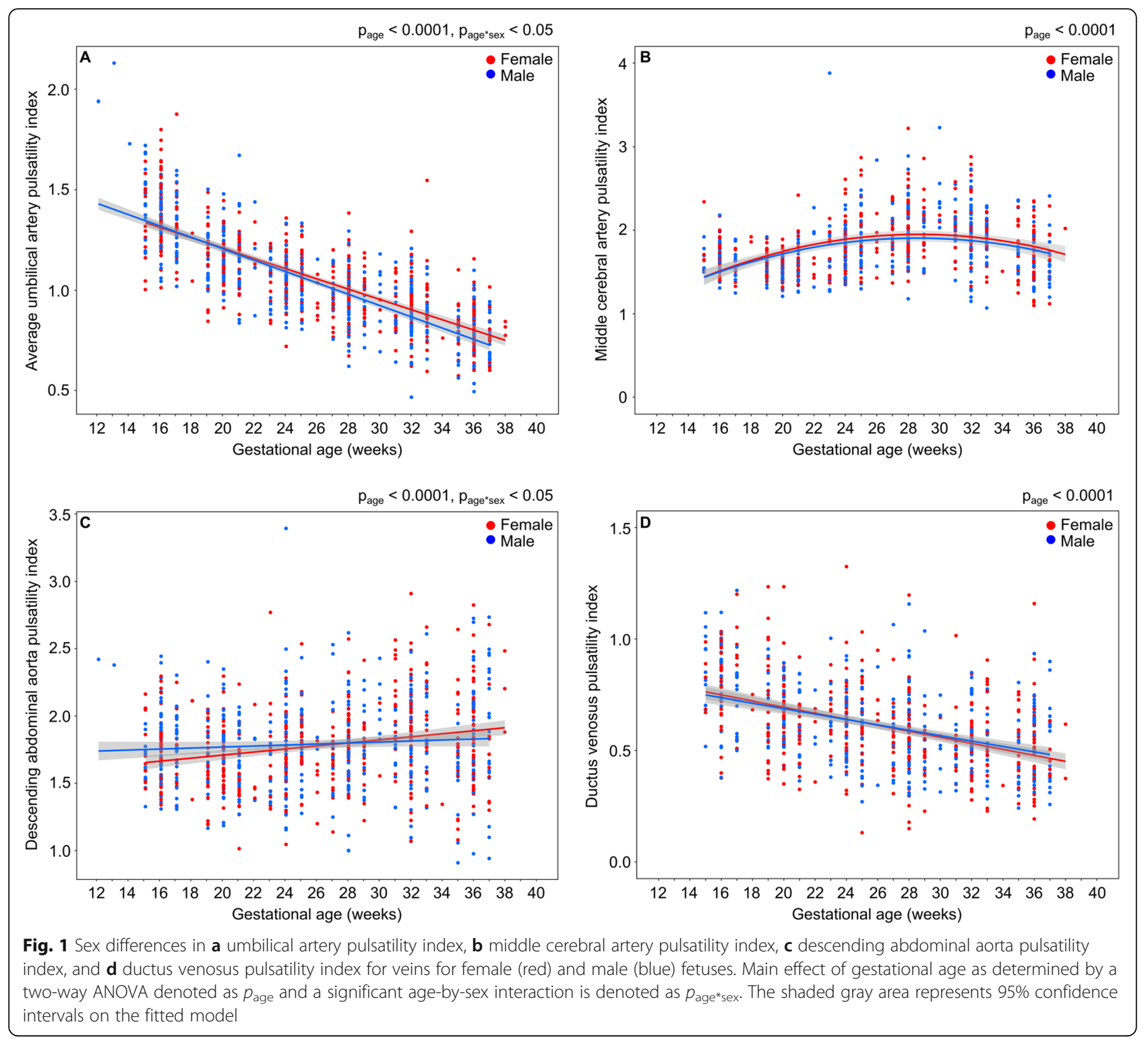

that the DAo PI changes more rapidly in females is consistent with studies in animal models that have demonstrated a greater capacity for female fetuses to redistribute blood flow [31, 32].

Another way that the fetal vasculature can respond to placental insufficiency is by a decrease in cerebral blood flow resistance, measured by the MCA PI and achieved by shunting of oxygenated blood through the ductus venosus $[33,34]$. Here, the trajectory of the MCA PI over gestation was consistent with previous work that reported an inverted U-shaped curve and a turning point at 30 weeks [8]. The DV PIV and PVIV also showed the expected decrease over gestation [7, 10]. The change over gestation did not depend on fetal sex for the MCA PI, DV PIV, and DV PVIV. A study by Prior et al. reported elevated MCA PI and umbilical venous flow (which feeds into the ductus venosus) in healthy female compared to male fetuses immediately before active labor [4]. The discrepancy in findings may be related to the timing of the examination (14-38 weeks gestation vs. in labor in [4]).

Measurement of the DV waveform during the first trimester is important for screening for fetal chromosomal abnormalities [35] and major cardiac defects [36]. Previous work investigated the influence of fetal sex on DV PIV and PVIV during the first trimester. The clinical findings in healthy pregnancies were heterogeneous with DV PIV found to be elevated in females in one study [37] and not statistically different between females and males in another [38]. More recently, the Trial of Umbilical and Fetal Flow in Europe (TRUFFLE) reported assessment of the DV throughout gestation, combined 
with computerized cardiotocography, is critical for guiding the timing of delivery [39]. This trial motivates the use of DV Doppler waveforms throughout gestation and our results suggest considerations of fetal sex do not need to be made when using DV PIV and PVIV for clinical decision-making. The current study was restricted to a cohort of healthy pregnancies and further research will be required to establish sex differences in fetal vascular responses to placental insufficiency in a population of complicated pregnancies. Our group has recently shown that uterine artery PI in healthy pregnancies did not differ between females and males, while in pregnancies complicated by either preeclampsia, preterm birth, or fetal growth restriction, male fetuses had a significantly altered trajectory over gestation [40].

The present study had several limitations. One is that we did not collect Doppler measurements during the first trimester. Another limitation is that while we aimed to standardize the approach for the fetal ultrasound examination, the measurements were collected at two study sites and by different operators which may have introduced inter-observer variability. Finally, while the number of participants in this study provided sufficient power to test the null hypothesis, the significant differences observed between female and male fetuses in this study were small and may not be clinically relevant. However, this data is consistent with the observation of sex-specific differences in pregnancy outcomes and raises interesting questions about the biochemical and physiological mechanisms associated with the sex differences. For example, women carrying female fetuses have higher concentrations of angiotensin II than women with male fetuses [41]. Angiotensin II is known to increase blood pressure through vasoconstriction and warrants further investigation as a possible mechanism responsible for the increased vascular resistance in the DAo and UA observed in female fetuses in this study.

\section{Perspectives and significance}

The principal finding of this work is that the trajectory of the UA and DAo PI over gestation in healthy pregnancies differed by fetal sex. Equally important, no sexspecific differences were found in MCA PI and DV PIV and PVIV over gestation. These four vessels are widely used to assess fetal well-being throughout pregnancy and these findings add to the growing evidence of sex differences in placental and fetal vascular development. Future investigations are needed to understand the underlying mechanisms for these sex differences and if these sex differences are maintained in pregnancies complicated by preeclampsia and fetal growth restriction.

\section{Authors' contributions}

ARC, NM, SS, CLW, and SRH performed the experiments. MW, SS, CLW, SRH, $A A B, J G S$, JCK, and LSC interpreted results of the experiments. DJ, HG, and LSC analyzed the data and drafted the manuscript. LS, WTP, AAB, CKM, JGS, JCK, and LSC conceived and designed the research. All authors read and approved the final version of the manuscript.

\section{Funding}

Funding for this work was provided by the Eunice Kennedy Shriver National Institute of Child Health and Human Development of Health Grant U01087177-01, the Banting Research Foundation and the Natural Sciences and Engineering Research Council of Canada.

\section{Availability of data and materials}

The datasets used and/or analyzed during the current study are available from the corresponding author on reasonable request.

\section{Declarations}

Ethics approval and consent to participate

The study was approved by the Institutional Review Boards of The Hospital for Sick Children (Toronto, ON, Canada, REB Number 1000051548), Mount Sinai Hospital (Toronto, ON, Canada, REB Number 15-0279-A), and Johns Hopkins Hospital University (Baltimore, MD, USA, IRB Number 0082717). All participants provided written informed consent to participate in the study.

Consent for publication

Not applicable.

\section{Competing interests}

The authors declare that they have no competing interests.

\section{Author details}

'Department of Chemistry, Memorial University of Newfoundland, 283 Prince Philip Drive, St. John's, NL A1B 3X7, Canada. ${ }^{2}$ Mount Sinai Hospital, Toronto, Ontario, Canada. ${ }^{3}$ Department of Obstetrics and Gynecology, University of Toronto, Toronto, Ontario, Canada. ${ }^{4}$ Division of Cardiology, Department of Paediatrics, The Hospital for Sick Children, Toronto, Ontario, Canada. ${ }^{5}$ Pregnancy Research Centre, Department of Obstetrics and Gynaecology, Royal Women's Hospital, Parkville, Australia. ${ }^{6}$ Toronto General Hospital Research Institute, University Health Network, Toronto, Ontario, Canada. ${ }^{7}$ Department of Immunology and Institute of Medical Sciences, University of Toronto, Toronto, Ontario, Canada. ${ }^{8}$ Women's College Research Institute, Women's College Hospital, Toronto, Ontario, Canada. ${ }^{9}$ Department of Pathology, Mount Sinai Hospital, Toronto, Ontario, Canada. ${ }^{10}$ Department of Laboratory Medicine and Pathobiology, University of Toronto, Toronto, Ontario, Canada. ${ }^{11}$ Centre for Fetal Therapy, Johns Hopkins Medicine, Baltimore, MD, USA. ${ }^{12}$ Translational Medicine, The Hospital for Sick Children, Toronto, Ontario, Canada. ${ }^{13}$ Department of Medical Biophysics, University of Toronto, Toronto, Ontario, Canada. ${ }^{14}$ Mouse Imaging Centre, The Hospital for Sick Children, Toronto, Ontario, Canada.

Received: 2 February 2021 Accepted: 1 March 2021

Published online: 10 March 2021

\section{References}

1. Broere-Brown ZA, Adank MC, Benschop L, Tielemans M, Muka T, Gonçalves $R$, et al. Fetal sex and maternal pregnancy outcomes: a systematic review and meta-analysis. Biol Sex Differ. 2020;11:26.

2. Widnes C, Flo K, Wilsgaard T, Kiserud T, Acharya G. Sex differences in umbilical artery Doppler indices: a longitudinal study. Biol Sex Differ. 2018;9: 16.

3. Acharya G, Ebbing C, Karlsen HO, Kiserud T, Rasmussen S. Sex-specific reference ranges of cerebroplacental and umbilicocerebral ratios: longitudinal study. Ultrasound Obstet Gynecol. 2020;56:187-95.

4. Prior T, Wild M, Mullins E, Bennett P, Kumar S. Sex specific differences in fetal middle cerebral artery and umbilical venous Doppler. PLoS ONE. 2013; 8:e56933.

5. Sonesson SE, Fouron JC, Drblik SP, Tawile C, Lessard M, Skoll A, et al. Reference values for Doppler velocimetric indices from the fetal and 
placental ends of the umbilical artery during normal pregnancy. J Clin Ultrasound. 1993;21:317-24.

6. Bahlmann F, Wellek S, Reinhardt I, Krummenauer F, Merz E, Welter C. Reference values of fetal aortic flow velocity waveforms and associated intra-observer reliability in normal pregnancies. Ultrasound Obstet Gynecol. 2001;17:42-9.

7. Kessler J, Rasmussen S, Hanson M, Kiserud T. Longitudinal reference ranges for ductus venosus flow velocities and waveform indices. Ultrasound Obstet Gynecol. 2006;28:890-8.

8. Ebbing C, Rasmussen S, Kiserud T. Middle cerebral artery blood flow velocities and pulsatility index and the cerebroplacental pulsatility ratio: longitudinal reference ranges and terms for serial measurements. Ultrasound Obstet Gynecol. 2007;30:287-96.

9. Guedes-Martins L, Cunha A, Saraiva J, Rita-Gaio A, Cerdeira AS, Macedo F, et al. Foetal aortic flow velocity waveforms in healthy and hypertensive pregnant women. Cardiovasc Ultrasound. 2014;27:1.

10. Turan OM, Turan S, Sanapo L, Willruth A, Berg C, Gembruch U, et al. Reference ranges for ductus venosus velocity ratios in pregnancies with normal outcomes. J Ultrasound Med. 2014;33:329-36.

11. Oros D, Ruiz-Martinez S, Staines-Urias E, Conde-Agudelo A, Villar J, Fabre E, et al. Reference ranges for Doppler indices of umbilical and fetal middle cerebral arteries and cerebroplacental ratio: systematic review. Ultrasound Obstet Gynecol. 2019;53:454-64.

12. Executive summary: hypertension in pregnancy, American College of Obstetricians and Gynecologists. Obstet Gynecol. 2013;122:1122-31.

13. Kramer MS, Platt RW, Wen SW, Joseph KS, Allen A, Abrahamowicz M, et al. A new and improved population-based Canadian reference for birth weight for gestational age. Pediatrics. 2001;108:E35.

14. Baschat AA, Güclü S, Kush ML, Gembruch U, Weiner CP, Harman CP. Venous Doppler in the prediction of acid-base status of growth-restricted fetuses with elevated placental blood flow resistance. Am J Obstet Gynecol. 2004; 191:277-84.

15. Hecher K, Campbell S, Doyle P, Harrington K, Nicolaides K. Assessment of fetal compromise by Doppler ultrasound investigation of the fetal circulation. Arterial, intracardiac and venous blood flow velocity studies. Circulation. 1995;91:129-38

16. Baschat AA, Weiner CP. Umbilical artery doppler screening for detection of the small fetus in need of antepartum surveillance. Am J Obstet Gynecol. 2000;182:154-8.

17. Viero S, Chaddha V, Alkazaleh F, Simchen MJ, Malik A, Kelly E, et al. Prognostic value of placental ultrasound in pregnancies complicated by absent end-diastolic flow velocity in the umbilical arteries. Placenta. 2004;25: 735-41.

18. Figueras F, Fernandez S, Eixarch E, Gomez O, Martinez JM, Puerto B, et al. Umbilical artery pulsatility index: reliability at different sampling sites. J Perinat Med. 2006;34:409-13.

19. Khare M, Paul S, Konje JC. Variation in Doppler indices along the length of the cord from the intraabdominal to the placental insertion. Acta Obstet Gynecol Scand. 2006;85:922-8.

20. Bhide A, Acharya G, Bilardo CM, Brezinka C, Cafici D, Hernandez-Andrade E, et al. ISUOG practice guidelines: use of Doppler ultrasonography in obstetrics. Ultrasound Obstet Gynecol. 2013;41:233-9.

21. Kiserud T, Piaggio G, Carroli G, Widmer M, Carvalho J, Neerup Jensen L, et al. The World Health Organization Fetal Growth Charts: A multinational longitudinal study of ultrasound biometric measurements and estimated fetal weight. PLoS Med. 2017;14:e1002220.

22. Owen P, Murphy J, Farrell T. Is there a relationship between estimated fetal weight and umbilical artery Doppler impedance indices? Ultrasound Obstet Gynecol. 2003;22:157-9.

23. Shiozaki A, Matsuda Y, Satoh S, Saito S. Impact of fetal sex in pregnancyinduced hypertension and preeclampsia in Japan. J Reprod Immunol. 2011; 89:133-9.

24. Elsmén E, Källén K, Marsál K, Hellström-Westas L. Fetal gender and gestational-age-related incidence of pre-eclampsia. Acta Obstet Gynecol Scand. 2006;85:1285-91.

25. Taylor BD, Ness RB, Klebanoff MA, Tang G, Roberts JM, Hougaard DM, Skogstrand K, Haggerty CL. The impact of female fetal sex on preeclampsia and the maternal immune milieu. Pregnancy Hypertens. 2018;12:53-7.

26. Huppertz B. Placental origins of preeclampsia: challenging the current hypothesis. Hypertens. 2008;51:970-5.
27. Soothill PW, Nicolaides KH, Bilardo CM, Campbell S. Relation of fetal hypoxia in growth retardation to mean blood velocity in the fetal aorta. Lancet. 1986;15:1118-20.

28. Laurin J, Lingman G, Marsál K, Persson PH. Fetal blood flow in pregnancies complicated by intrauterine growth retardation. Obstet Gynecol. 1987;69: 895-902.

29. Madazli R, Uludağ S, Ocak V. Doppler assessment of umbilical artery, thoracic aorta and middle cerebral artery in the management of pregnancies with growth restriction. Acta Obstet Gynecol Scand. 2001;80: 702-7.

30. Baschat AA. Fetal responses to placental insufficiency: an update. BJOG. 2004;111:1031-41.

31. Cahill LS, Shinar S, Whitehead CL, Hobson SR, Stortz G, Ayyathurai V, et al. Sex differences in modulation of feto-placental vascular response in growth-restricted mouse fetuses following betamethasone administration: comparisons with human fetuses. Am J Obstet Gynecol MFM. 2021;3: 100251.

32. Thompson LP, Turan S, Aberdeen GW. Sex differences and the effects of intrauterine hypoxia on growth and in vivo heart function of fetal guinea pigs. Am J Physiol Regul Integr Comp Physio. 2020;319:R243-54.

33. Cohn HE, Sacks EJ, Heymann MA, Rudolph AM. Cardiovascular responses to hypoxemia and acidemia in fetal lambs. Am J Obstet Gynecol. 1974;120: 817-24

34. Kiserud T. Physiology of the fetal circulation. Semin Fetal Neonatal Med. 2005; 10:493-503.

35. Matias A, Gomes C, Flack N, Montenegro N, Nicolaides KH. Screening for chromosomal abnormalities at 10-14 weeks: the role of ductus venosus blood flow. Ultrasound Obstet Gynecol. 1998;12:380-4.

36. Toyama JM, Brizot ML, Liao AW, Lopes LM, Nomura RMY, Saldanha FAT, et al. Ductus venosus blood flow assessment at 11 to 14 weeks of gestation and fetal outcome. Ultrasound Obstet Gynecol. 2004;23:341-5.

37. Prefumo F, Venturini PL, De Biasio P. Effect of fetal gender on first-trimester ductus venosus blood flow. Ultrasound Obstet Gynecol. 2003;22:268-70.

38. Teixeira LS, Leite J, Castro Viegas MJB, Faria MML, Pires MC, Teixeria HC, et al. Non-influence of fetal gender on ductus venosus Doppler flow in the first trimester. Ultrasound Obstet Gynecol. 2008;32:12-4.

39. Lees CC, Marlow N, van Wassenaer-Leemhuis A, Arabin B, Bilardo CM, Brezinka C, et al. 2 year neurodevelopmental and intermediate perinatal outcomes in infants with very preterm fetal growth restriction (TRUFFLE): a randomised trial. Lancet. 2015;385:2162-72.

40. Paranavitana L, Walker M, Ravi Chandran A, Milligan N, Shinar S, Whitehead $\mathrm{CL}$, et al. Sex differences in uterine artery Doppler during gestation in pregnancies complicated by placental dysfunction. Biol Sex Differ. 2021;12: 19.

41. Sykes SD, Pringle KG, Zhou A, Dekker GA, Roberts CT, Lumbers ER. The balance between human maternal plasma angiotensin II and angiotensin 17 levels in early gestation pregnancy is influenced by fetal sex. Journal Renin-Angiotensin-Aldosterone Syst. 2014;15:523-31.

\section{Publisher's Note}

Springer Nature remains neutral with regard to jurisdictional claims in published maps and institutional affiliations.

Ready to submit your research? Choose BMC and benefit from:

- fast, convenient online submission

- thorough peer review by experienced researchers in your field

- rapid publication on acceptance

- support for research data, including large and complex data types

- gold Open Access which fosters wider collaboration and increased citations

- maximum visibility for your research: over $100 \mathrm{M}$ website views per year

At BMC, research is always in progress.

Learn more biomedcentral.com/submissions 